\title{
Neutral Interest Rates in CEEMEA - Moving in Tandem with Global Factors
}

\author{
Clemens Grafe, Goldman Sachs Global Investment Research* \\ Sara Grut, Goldman Sachs Global Investment Research* \\ Lorenzo Rigon, Stanford University ${ }^{\star}$
}

The decline in long term interest rates in the first decade of this millennium and a slow response of output to very lower interest rates post the global financial crisis in developed countries has sparked renewed interest into estimates and drivers of the so called neutral rate. In this article we contribute to this discussion by applying an open economy version of the Kalman filtering approach pioneered by Laubach and Williams to a number of emerging economies of the European time zone. We find that the decline in neutral interest rate in most of the countries we analyse mirrors that elsewhere, but that unlike in more developed countries very little of that decline can be attributed to declines in potential growth rates. Instead we find that estimates of US neutral rates can explain the overwhelming part of the dynamics in neutral rates in the region and we provide estimates of the elasticities to US rates. The exception is Russia where we cannot attribute any significant part of the dynamics in neutral rates to either Russia's trend growth or the US neutral rate. Instead, we conjecture that in the last two decades neutral rates have been mostly driven by persistent terms of trade shocks.

Keywords: neutral rate, US neutral rate, Russian neutral rate, terms of trade, terms of trade shocks, potential output growth, zero lower bounds

JEL: C5, E43, E52

\section{Introduction}

Central banks can typically add or withdraw stimulus from an economy by targeting some short-term market interest rate. By doing so, they usually attempt to meet a nominal target, which these days takes the form of an inflation target for most Central Banks. Apart from the current exchange rate the judgement of whether or not a Central Bank should raise rates involves a view on a number of variables such as potential growth, defined as the rate at which an economy can expand that operates at full capacity without adding to price pressures. The neutral

\footnotetext{
* The views expressed here are solely those of the authors and do not necessarily reflect those of others at Goldman Sachs International or Stanford University.
} 
or natural rate of interest is then defined as the real interest rate that a Central Bank needs to target if it was to keep the economy at capacity. Assuming a Central Bank succeeds in keeping rates close and symmetric around its inflation target, it can be thought of as the intercept of the Taylor rule that appropriately describes the Central Bank's reaction function minus the inflation target.

While the concept of natural or neutral interest rates is quite intuitive, the rate is not observable. Even worse and as outlined above the identification requires as inputs other unobservable variables such as a measure of spare capacity and potential growth. Consequently, any estimate will necessarily be imprecise and the concept has its critics as a useful tool for policy making. Milton Friedman for instance argued against natural rate-based policies in his presidential address to the American Economic Association, positing that "One problem is that [the policymaker] cannot know what the 'natural' rate is. Unfortunately, we have as yet devised no method to estimate accurately and readily the natural rate of either interest or unemployment. And the 'natural' rate will itself change from time to time."

The latter is key, if we could assume that potential growth and the natural rate were time invariant, this would clearly help to identify both. However, any growth model illustrates that neutral rates are unlikely to be stable. The real interest rate even in the most basic closed economy non stochastic growth models is typically a function of time preferences, i.e. to which extent people value the future and hence want to save as well as the growth rate of total factor productivity, population growth and the intertemporal elasticity of substitution. In open economy models, global equivalents of the above will matter as well. In practice, the rate is likely to also depend on the regulatory framework, lending standards, quality of balances sheets and persistent terms of trade shocks among others. Many of these factors are unlikely to be time invariant and hence we cannot just calculate the rate by taking arbitrarily long averages. Neither are the factors influencing the neutral rate and their influence on rates easily observable.

That said even though we might not be able to write an algorithm that allows Central Banks to know the neutral rate at a given point in time, implicitly policy makers are arguably forced to make an assessment about the level of neutral rates when setting policy rates. Thus, though imprecise, having an estimate appears better than not having one.

While the concept of neutral rates is more than a hundred years old, having originally been proposed by Knut Wicksel (1898), it has received significantly more attention in the last decade for exactly the reasons, the rate is difficult to pin down. Until the turn of the millennium, long term averages of real rates did not display any obvious trend and hence simple averages were usually seen as good enough indicators of neutral rates. However, in the current millennium, long term interest rates net of the inflation targets started to decline. This process accelerated post the global financial crisis sparking renewed interest in applying more advanced econometric methods to estimate the path of neutral rates. 
In this article, we contribute to this literature by applying a method first used in Laubach and Williams (2003) to some emerging countries of the European time zone (summarised under the acronym CEEMEA in what follows $)^{2}$. There have been studies that have looked at individual countries in the region (Kreptsev et al. (2016) for Russia, Us (2018) for Turkey, Kuhn et al. (2017) for South Africa, Stefanski (2017) for CEE) but to the best of our knowledge this is the first contribution that uses the same framework across different countries which allows us to make some inferences that those papers couldn't. Also with the exception of Kuhn et al. (2017) the papers use closed economy models while we use the small open economy as proposed by Berger et al. (2014) or Pedersen (2015).

For most countries our estimated dynamics for neutral rates displays a similar dynamics to that found in other countries. They fell from the beginning of the millennium but have largely stabilised from 2011-2012 onwards. We find two exceptions: In Hungary, our estimates suggest the neutral rate is still declining (though it remains above that in Poland for instance); More interestingly, Russian neutral rates fell in tandem with others early on, but while others continued to fall, Russian neutral rates have risen since the global financial crisis (GFC). Overall, neutral rates in Poland, Hungary and Romania appear to be converging to levels quite close to those found by others for small open economies in Europe, while in the Czech Republic and Israel neutral rates have effectively fallen to similar levels seen in the developed world (in the Czech Republic this is arguably owing to that country's peg to the Euro).

In the standard model from Berger et al., that in line with Laubach and Williams (2016) models the neutral rate as a function of a country's trend growth rate and a non-observable factor that is modelled as a random walk, we only attribute a very small part of the decline in neutral rates to the potential growth rate, a result that is very much in line for instance with Carrillo and Polly's (2014) work on Mexico. However we find strong co-movement between the unobservable random walk variable and US neutral rates.

We hence complement the results of the standard model with those of a model where we use the US neutral rate as an exogenous input. We find that the US rate and its covariance with the unobserved factor in most cases explains more than $80 \%$ of the variation. One again, the exception is Russia, where we have to attribute all the variation to the unobservable factor.

The second model also allows us to make some inference on the impact of US neutral rates on the neutral rates in the countries we studied. We find quite high elasticities ranging from 4.1 in Turkey to close to 1 in the Czech Republic and Hungary and 0.2 in Russia though the latter is clearly only very imprecisely measured given the above.

\footnotetext{
${ }^{2}$ The countries we look at are the Czech Republic, Hungary, Poland, Romania, Israel, Turkey, South Africa and Russia.
} 
We fail to identify either Russia growth or US interest rates as drivers of Russian neutral rates. In fact the correlation between Russian neutral rates and trend growth appears to be negative. As we argue below, the correlation between Russian neutral rates and persistent changes in Russia's Terms of Trade instead is quite strong and likely to dominate the other factors. Expectations of trending terms of trade in the future are likely to translate into a trend in future real exchange rates which will influence not only short term real interest rates but even longer term ones. If this conjecture proved right, a view of range bound terms of trade would imply a significant reduction in neutral rates in commodity producing countries like Russia in the years ahead.

\section{Literature Review}

Though the concept of neutral interest rates exists for more than a century, attempt to identify it intensified post the millennium when long term interest rates started to display what seemed a trend decline.

The strand of the literature that our contribution best fits into goes back to the seminal paper by Laubach and Williams in 2003, which proposes a joint estimation of the natural rate of interest, potential output, and its trend growth rate using a Kalman Filter. In their approach they model the natural rate for the US as a function of US growth and an unobservable variable meant to pick up the impact of changes other than growth such as shifts in savings rates due to changes in population growth, time preference, regulation etc. They estimate that between 1960 to 2003 the neutral rate in the US varied significantly between a peak of about $4.5 \%$ in the mid 60 s and a minimum of $1.25 \%$ in the early nineties. However they found no secular trend with their estimate for the end of their observation period being close the period average at about $3 \%$.

In their specification, the beta of the real rate vs potential output is close to one but a significant part of the variation in the trend growth rate is explained by the unobservable factor. In fact, on their estimates US trend growth is reasonably stable. Thus, as Hamilton et al. (2015) point out, neutral rates even for the US are statistically not as closely linked to US growth as is often thought ${ }^{3}$.

An alternative strand of investigations into the neutral rate uses stochastic dynamic equilibrium models (e.g. Giammariou et al., 2003). These models have their advantages if the focus is on evaluating different monetary policy rules for instance in a cost/benefit analysis, but that comes at the price that the estimate of the neutral rate is likely to be quite model dependant. Also they are ill suited to incorporate structural parameters of the model that are not possibly not time invariant. Still the estimate Giammariou et al. (2003) obtained on the neutral

\footnotetext{
${ }^{3}$ Consequently the decline in neutral rates since the GFC is quite plausibly not a sign of a sizeably permanent decline in trend growth or a secular stagnation (Summers, 2014) but by factors such as changes in regulation, long lasting balance sheet effects that hold back the recovery etc.
} 
rate in the Euro area in 1994-2000 was very close to that obtained by Williams and Laubach over the same period, a period of relative stability in trend growth and long term interest rates.

Laubach and Williams followed up their earlier paper in 2015 extending the data set into the period post the Great Recession. While results for the earlier period confirm those in Laubach (2002), they found that the natural rate had declined post the Global Financial Crisis (GFC) to levels close to zero and remained at these levels even during the recovery phase. Their model ascribes about half of the decline to lower trend growth but other factors appear to be at work as well that are less easy to pin down.

Holston et al. (2016) apply the same techniques to other developed G7 economies, Canada, the Euro area and the UK. They find that neutral rates in all three declined similarly to the US and indeed display a substantial degree of co movement, suggesting a significant influence of a global factor in determining the rates. Using a Cholesky decomposition the authors find a great deal of interdependence with shocks to the US neutral rate contributing about 35\% of the variation in Canadian rate on a 10 year horizon and further but smaller contributions from the other two regions. While the US rate is less dependent on others even for the US they find in total about $20 \%$ of the variation being driven by shocks to other rates. The co-movement in rates driven by global factors as well as that even in theory, a country's neutral rate must to some extent depend on global rates is necessarily a larger constraint on applying the Laubach Williams framework the more open and smaller the economy is.

Berger and Kempa (2014) present an extension of the framework to the open economy and apply it to Canada. Pedersen (2015) uses a similar framework and applies it to Denmark. We largely follow this open economy approach in our analysis.

More recently, researchers have started to apply the same approach to emerging economies. Perelli and Roach (2014) apply different filtering techniques including the approach discussed above to real interest rates in emerging economies (EM) finding that the secular decline of real interest rates in many EM's already started in 2002 and prior to the GFC. Not surprisingly they find that common global factors play an important role in the determination of neutral rates in EM. Carrillo and Polly (2014) apply the Laubach approach to Mexico. While they similarly to the DM literature find a sharp decline in the neutral rate from about $3 \%$ pre-GFC to about $1 \%$ post the GFC, only a very small part of that decline can be attributed to the variation in Mexico's trend growth rate with most of it being explained by the model omitted factor, again finding that the standard closed economy Laubach/ Williams (LW) model is less well suited for open small economies. 
Kreptsev et al. (2016) analyse the relationship of the equilibrium interest rate in Russia with potential GDP growth and global interest rates and extend the investigation into estimating neutral rates using the standard LW framework. Because short term money market rates were negative in real terms prior to the GFC, they use the short term bank lending rates which as the authors recognize themselves is problematic to use as a risk free rate and hence the results need adjustments. They find a neutral rate close to $3 \%$ for the lending rate in Russia but given a 250bps spread between money market rates and the lending rate used this would imply a neutral short term money market rate of $0.5 \%$.

Kuhn et al. (2017) apply an open economy version of the LW framework to South Africa and use Bayesian techniques instead of the maximum likelihood method. They find no secular trend in the neutral rate till the GFC but a significant decline thereafter with neutral rates declining from around 3\% pre GFC towards $1.5-2 \%$. While prior to the GFC the upside pressure on neutral rates from rising trend growth were balanced by downside pressure of the non observable factor, post the GFC the decline is mostly associated with a decline in domestic trend growth. They attribute most of the dynamics in the non observable factor to changes in the South Africa's CDS and changes in the EM current accounts which they use as a measure for excess EM savings putting downside pressure on global rates.

\section{Model}

Given our focus on emerging economies, we take two different approaches. First, we use the New Keynesian small open economy model proposed by Berger at al. (2014) and Pedersen (2015). The model includes four measurement equations for the following observable variables: real GDP (in logs), inflation, real interest rate and real effective exchange rate (REER). The first three measurement equations decompose the observable variables (with no observation noise) into two states: a trend state and a gap state. The fourth one models inflation deviations from a long term "regime" level.

The trend (or potential) real GDP follows a local linear growth model, adding to the past level of trend GDP a random innovation and a potential growth state, which in turn is modelled as a random walk plus noise. The real GDP gap is derived from an IS curve that includes the past two lags of the GDP gap, the real rate gap and two lags of the REER gap, plus a random shock.

Inflation is determined by a Phillips curve that combines the past level of inflation, the GDP gap, real exchange rate appreciation and a long term "mean" capturing the structural break between different inflation regimes. 


\section{Real Output:}

RGDP Trend and Gap decomposition: $\quad y_{t}=y_{t}^{N}+x_{t}^{y}$

Local Linear Growth model for RGDP Trend: $\quad y_{t}^{N}=y_{t-1}^{N}+g_{t-1}+\varepsilon_{t}^{N y}$

...where RGDP Trend Growth is Random Walk $\quad g_{t}=g_{t-1}+\varepsilon_{t}^{g}$

IS curve for GDP Gap

\section{Inflation:}

$$
x_{t}^{y}=\alpha_{0}^{y} x_{t-1}^{y}+\alpha_{1}^{y} x_{t-2}^{y}+\alpha_{0}^{r} x_{t-1}^{r}+\alpha_{0}^{q} x_{t-1}^{q}+\alpha_{1}^{q} x_{t-2}^{q}+\varepsilon_{t}^{x y}
$$

Open Economy Phillips Curve by regimes:

$$
\pi_{t}=\pi_{\text {regime }}+\beta_{\pi} \pi_{t-1}+\kappa_{y} x_{t-1}^{y}+\beta_{q} \Delta q_{t-1}+\varepsilon_{t}^{\pi}
$$

\section{Real Interest Rates :}

R. Rates Trend and Gap decomposition:

Natural Rate from Trend Growth...

... and from Random Walk transitory level

Real Interest Parity for R. Rates Gap...

...plus AR(1) Risk Premium

$$
r_{t}=r_{t}^{N}+x_{t}^{r}
$$$$
r_{t}^{N}=\gamma g_{t-1}+z_{t-1}
$$

$$
z_{t}=z_{t-1}+\varepsilon_{t}^{Z}
$$$$
x_{t}^{r}=c x_{t-1}^{q}+h_{t-1}
$$$$
h_{t}=\rho h_{t-1}+\varepsilon_{t}^{h}
$$

\section{Real Effective Exchange Rate (REER):}

REER Trend and Gap decomposition:

$$
q_{t}=q_{t}^{N}+x_{t}^{q}
$$

Natural REER is Random Walk (from PPP):

$$
q_{t}^{N}=q_{t-1}^{N}+\varepsilon_{t}^{N q}
$$

REER Gap is $\mathrm{AR}(2)$

$$
x_{t}^{q}=\delta_{0} x_{t-1}^{q}+\delta_{1} x_{t-2}^{q}+\varepsilon_{t}^{q}
$$

Note: The first equation in each set is a measurement equation, the other equations are state equations. The observation error or state innovation terms $\varepsilon_{t}^{\text {are Gaussian white }}$ noises with $\sigma^{\mathbf{\prime}}$ dispersion. In the alternative model, trend growth is replaced by US Natural Rate in the Natural Rate equation.

In the second approach, we include the US neutral rate (as measured by LW) as an exogenous determinant of the other countries' neutral real rate, instead of the domestic trend growth. The reason for this choice is that a significant part of the trend dynamics in the first framework tends to be captured by the random walk component, suggesting this is indeed capturing global factors (this was also noted by Carrillo et al., 2014). 


\section{Methodology}

To solve the model, we use a Maximum Likelihood approach. We acknowledge that the parameter estimation would ideally be done with Bayesian methods, as Maximum Likelihood methods face the "pile up" problem biasing the estimates. Pedersen (2015) indeed follows Berger and Kempa (2014) to set up a Bayesian Estimation. We constrain the MLE optimisation transforming the parameter space with sigmoid transformations in order to rule out solutions that would be inconsistent with:

- Stationarity (e.g. AR(1) parameters $<\|1\|)$

- Theoretical sign restrictions (e.g. REER appreciation is contractionary)

- Reasonable ranges of parameter values as implied by preliminary regressions on trends and gaps from univariate HP filters

The third restriction implies that the objective of the estimation is not so much that of achieving correct inference on the 'true' parameter values, which would require more sophisticated techniques (see Stock and Watson, 1998 and Kim and $\mathrm{Kim}, 2013)$. It is rather that of finding a set of parameter values that can reconcile a standard HP distinction of trends and gaps into a complete and theoretically grounded econometric model. A synthetic outline of the estimation method is as follows:

- First, a PELT algorithm is used to identify inflation regimes (i.e., dummies to identify structural changes in inflation). The minimum length of a regime is set to 20 quarters.

- Set up transformations of parameter space from model to estimation scale. Theoretical and stationarity restrictions on parameter space are further refined with "reasonable range" bounds derived as follows:

- Use univariate HP filters to get preliminary trends and gaps

- Use simple OLS regression estimates between the preliminary trends and gaps to get preliminary analogs of model equations

- Use a (5\%-95\%) confidence interval around estimated parameters to get restrictions for the parameter space of the betas

- Use dispersion of residuals to derive lower bounds for parameter space of the sigmas, addressing "pile up" problem with their maximum likelihood estimation (MLE)

Restrictions on parameter space are enforced with logistic transformation. In the case of $\mathrm{AR}(2)$ restrictions, which involve dependence, we use nested logistic transformations:

- Prior for states' initial values and prior variances

- From preliminary trends and gaps, and estimated variances

- MLE: minimization of negative log-likelihood 
- Simulated Annealing: from 10 starting points extracted from uniform distribution between upper and lower bound of parameter space. Computations are parallelized on all cores available to the machine. The ten final estimates are aggregated with an average weighted by a transformation of their relative likelihood

- For filtering and smoothing, we apply Kalman recursive formulas.

\section{Data}

We use the above methodology to estimate the neutral rates for the Czech Republic, Hungary, Poland, Israel, Turkey, South Africa and Russia. As inputs we use seasonally adjusted quarterly data for core inflation from 1990Q1 to 2017Q3 (annualised first difference of the log CPI excluding food and energy) provided by the OECD, GDP (log multiplied by 100) taken from the IMF and the real effective exchange rate calculated by the IMF. For the nominal interest rates, we use the average quarterly interbank rates provided by the OECD when available. Where this data is not available, we used the discount rate also provided by the OECD. For the real interest rates, we take the difference between the nominal interest rate and inflation expectations for the next year. We calculate inflation expectations as the average inflation over the four quarters ahead from a univariate $\mathrm{AR}(3)$ of inflation estimated over a 36 quarter rolling window.

\section{Results}

\subsection{Domestic trend growth model - CEEMEA neutral rates are moving in tandem}

Using the first modelling approach with trend growth rates, we find that neutral rates have declined and then stabilised in most countries across CEEMEA, with the exception of Hungary, where neutral rates are still declining (Figure 1), and Russia, where neutral rates have reversed their decline in 2009 and continued to rise since (Figure 2).

The broad decline in neutral rates across CEEMEA (Figure 3) is in line with studies done on the developed world. In DM, most authors find that neutral rates in the US specifically, but also in Europe, started to decline at the beginning of this century, and that the decline accelerated during and post the Global Financial Crisis only to stabilise in recent years (see Holston et al., 2016).

- Neutral rates have fallen in CEE-4 similarly to DM: In the Czech Republic, Hungary, Poland, and Romania, neutral rates are now $0.0 \%$, $1.3 \%, 2.5 \%$ and $2.3 \%$, respectively. Neutral rates in Poland and Romania have especially declined from elevated levels, with most of the decline 
Figure 1. Neutral rates have declined and stabilized in Israel, Poland and Czech, but are still declining in Hungary

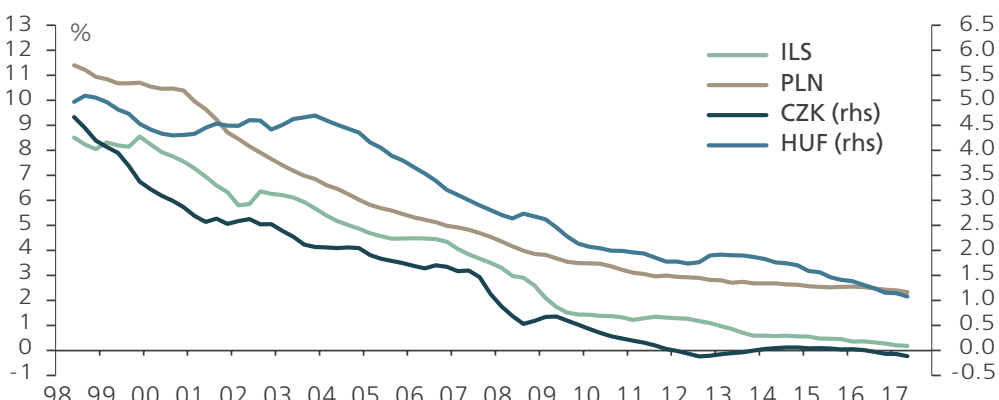

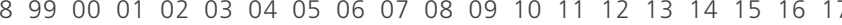

Note: Baseline Model Neutral Real Rate

Source: Goldman Sachs Global Investment Research

Figure 2. Neutral rates have declined and are stabilising in South Africa, Turkey and Romania, but continue to rise in Russia

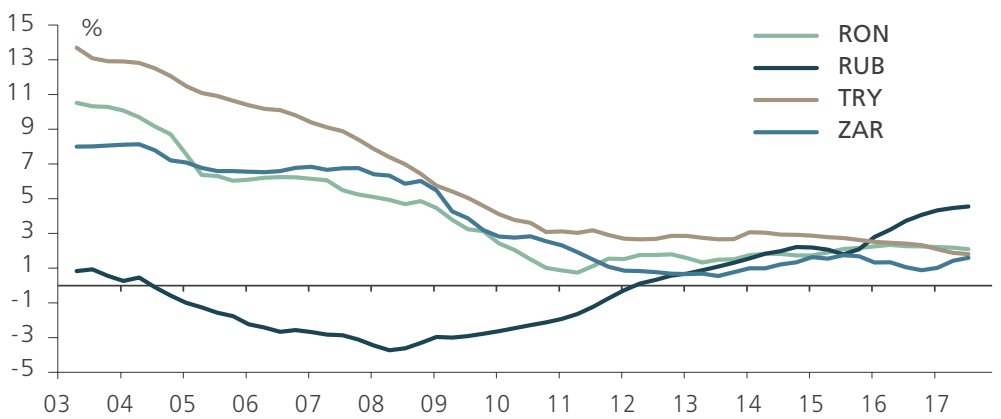

Note: Baseline Model Neutral Real Rate

Source: Goldman Sachs Global Investment Research

Figure 3. The overall decline in neutral rates in CEEMEA is consistent with findings across DM countries

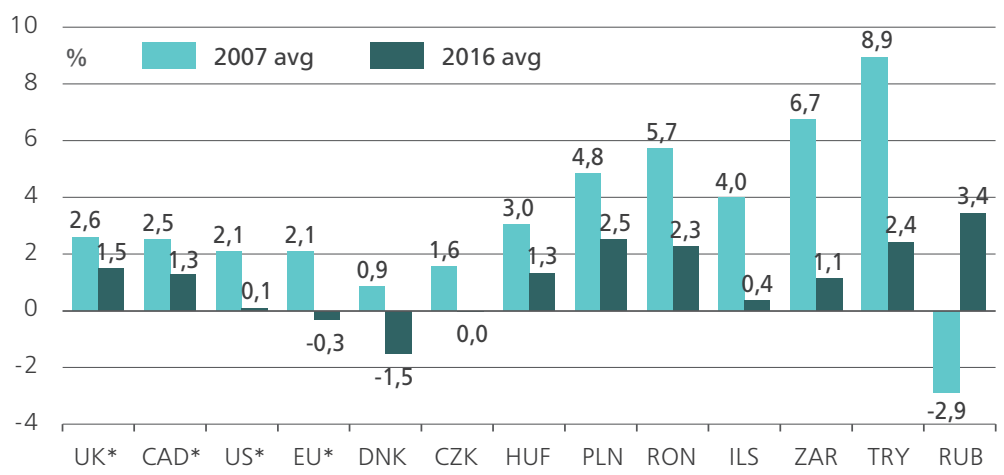

Note: Baseline Model Neutral Real Rate

Source: Goldman Sachs Investment Research; Holston et al. (2016) 
seen before the GFC, where neutral rates were lower in the Czech Republic and Hungary (Figure 3). The declines in neutral rates since 2007 have been of similar magnitude to those estimated for the Eurozone and the US, but larger than those observed for Canada or the UK. In Hungary, neutral rate estimates are now in line with the levels observed in the UK and Canada, but remain distinctly above those observed in the Eurozone or the US. In the case of Hungary, neutral rates are still falling and appear to be converging towards the level of the Eurozone and the US, while in the Czech Republic this convergence appears to have taken place already.

- The decline in neutral rates in South Africa, Israel and Turkey is of a larger magnitude. In South Africa and Israel, neutral rate estimates have fallen from around $9.0 \%$ to $1.1 \%$ and $0.4 \%$, respectively, thus to levels similar to those observed in the DM world. In Israel, the decline was gradual, while the decline accelerated for South Africa following the GFC. In Turkey, neutral rates fell from $14 \%$ to $3 \%$, with most of the decline taking place after the GFC. While the level in Turkey remains well above that in DM countries, it is closing in on those in some CEE countries.

- Neutral rates continue to rise in Russia. The real outlier in the region is Russia, where the neutral rate has risen sharply from the negative values recorded in the pre-GFC period. Neutral rates reached a minimum around mid- 2008 of $-4.0 \%$ and have now reached $4.0 \%$, with a continued gradual increase. In our view, the reasons behind this peculiar trend involve a combination of the change in the dynamics of the terms of trade, together with a structural break in monetary policy from a heavily managed float to inflation targeting. The rising oil prices pre-GFC, together with a managed exchange rate, kept real rates negative, while the falling oil prices since the GFC are sustaining the growth of the neutral rate as they have led to a trend real depreciation in the exchange rate. However, this also implies that the neutral rate in Russia will decline if oil prices fully stabilise.

As Holston et al. (2016) note in the estimates for the DM world, though they use closed economy models, the rates clearly show evidence of co-movement, suggesting an important role of global factors in shaping the dynamics of trend growth and neutral rates across countries. Similarly Carrillo et.al. (2014) found that most of the dynamics of the neutral rate in Mexico are not driven by the countries trend growth, but rather by the unobserved random process. In turn they also conjecture that this random process appears to co-move with longerterm US rates. 


\subsection{Introducing the US neutral rate works well as a determinant of CEEMEA neutral rates}

We complement the above analysis by including US neutral rates as estimated by LW into our model instead of trend growth. Overall, the results are similar to the baseline model, with Turkey being the only country with markedly different results. In Turkey, the second model approach suggests an even steeper decline in neutral rates, to $0.0 \%$ instead of $3.0 \%$.

Figure 4. Using the US neutral rate instead of the trend growth rate yields similar results ...

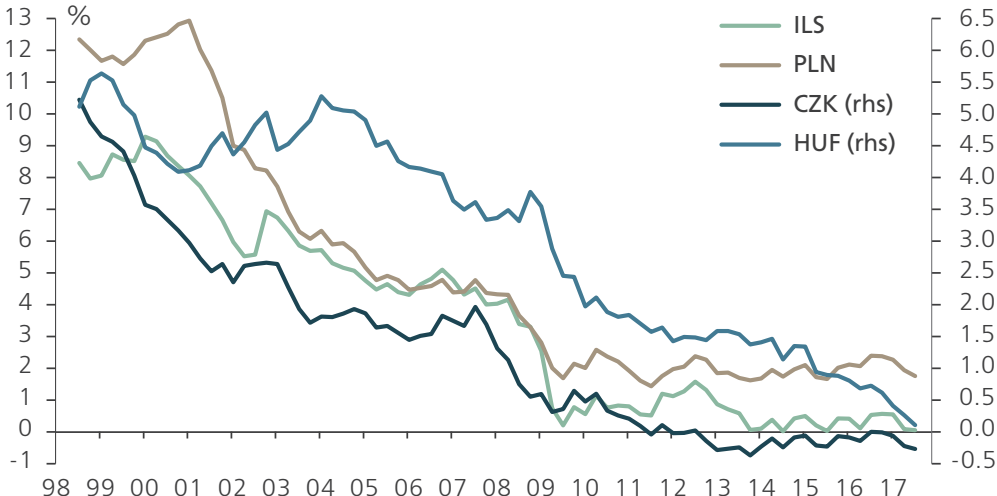

Note: Neutral Real Rate (second model)

Source: Goldman Sachs Global Investment Research

Figure 5. .... with neutral rates stabilizing in most of CEEMEA, except for Hungary and Russia

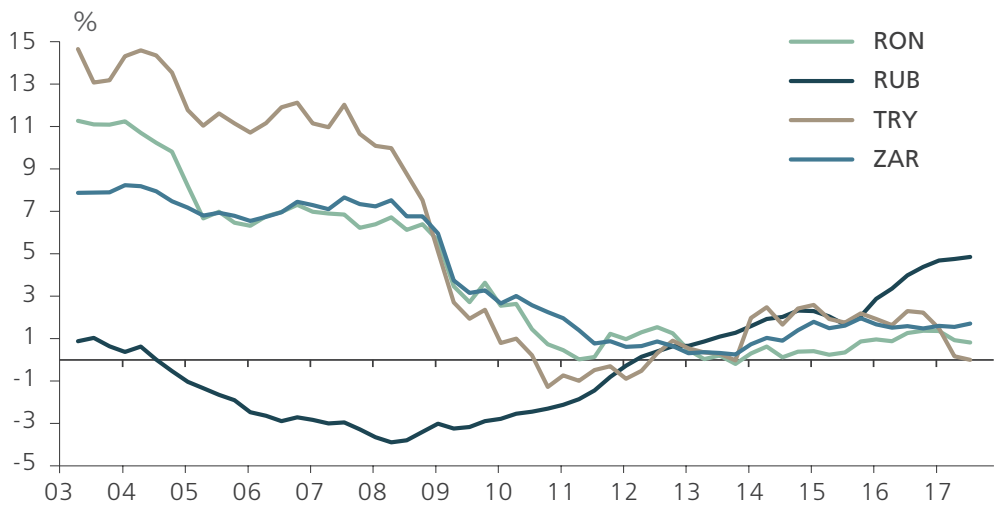

Note: Neutral Real Rate (second model)

Source: Goldman Sachs Global Investment Research 
While the results are broadly similar, the coefficients on trend growth are generally weaker than the coefficient for the US neutral rate, suggesting that the baseline model is being driven by global factors, rather than domestic ones:

- The impact of trend-growth on neutral rates is relatively small: In the baseline specification, we find a coefficient for trend growth onto neutral rates which is close to zero for most economies (Figure 6), with the exception of Romania and South Africa, where the beta is 0.8 and 1.9 respectively. Thus, the low beta's suggest that most of the variation in neutral rates are unexplained (Figure 8).

- We find a high beta for the US neutral rate in driving neutral rates across CEEMEA: Across the CEE-4, the coefficient to US neutral rate is

Figure 6 . The beta of neutral rates to domestic trend growth is low across the region...

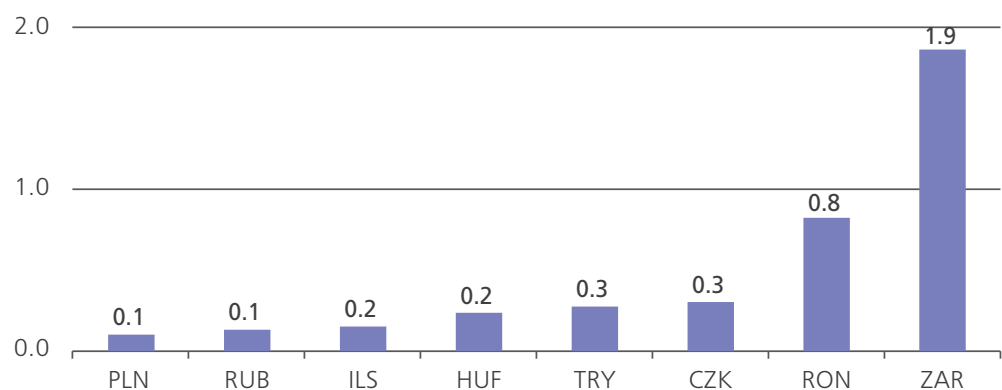

Note: Figure shows the annualised coefficient of trend growth to neutral rates (baseline model)

Source: Goldman Sachs Global Investment Research

Figure $7 . .$. while the beta to the US neutral rate is relatively high across CEEMEA

5.0

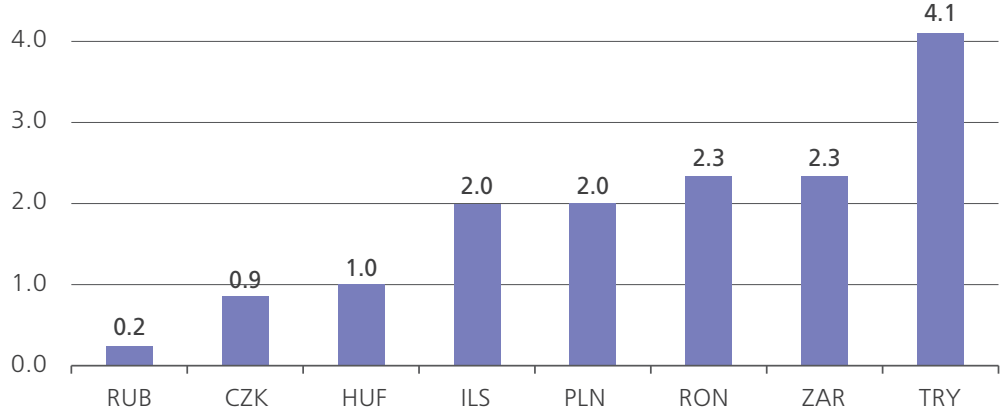

Note: Estimates for Alternative Model

Source: Goldman Sachs Global Investment Research 
around 1.0 for the Czech Republic and Hungary, and around 2.0 for Poland and Romania (i.e. a 1ppt change in the US neutral rate lowered neutral rates in these countries by $90 \mathrm{bps}$ and 200bps, respectively; Figure 7). Comparing this result with the magnitude of the trend decline in neutral rates over the two in-sample shows that the US rate, scaled by its coefficient, can account for around 50\% of the decline in all four countries (Figure 9).

For Israel, South Africa and Turkey the betas are around 2.0, 2.3 and 4.1 respectively, and the change in the US neutral rate can account for $66 \%, 80 \%$ and $85 \%$ of the neutral rate declines in the respective full samples. If we include the covariance between the US neutral rate and the risk premium, we find that more than $75 \%$ of the variation in neutral rates can be explained. Again, the true outlier

Figure 8. The random walk component captures most of the variation in neutral rates in the baseline model ...

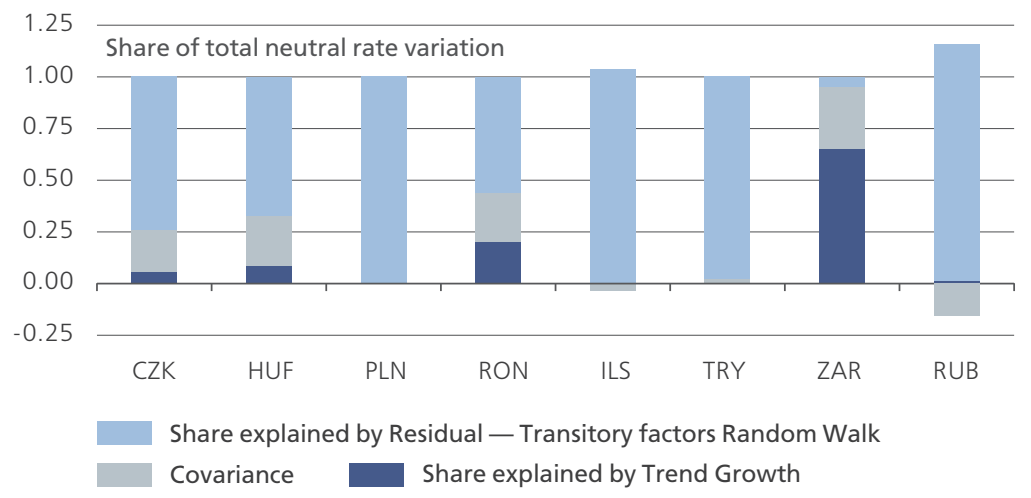

Source: Goldman Sachs Global Investment Research

Figure 9.... while the US neutral rate explains most of the variation in the alternative model

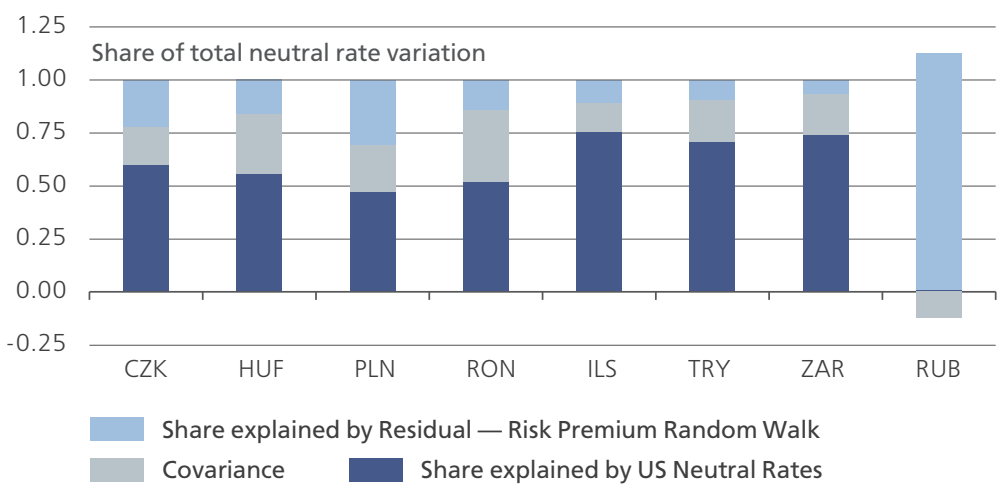

Source: Goldman Sachs Global Investment Research 
is Russia, as its peculiar dynamic of real rates does not correlate with US neutral rate dynamics, and thus results in an insignificant coefficient (Figure 7).

Thus, the two separate approaches suggest that the trend US rate explains most of the different degrees to which neutral rates in CEEMEA have declined in the past. This suggests that global factors, such as the US neutral rate, are more important drivers of neutral rates in a small open economy than domestic growth.

\subsection{Combining Trend Growth with the US Neutral Rate}

To fully understand which factors drive the neutral rate (i.e., whether this is driven by domestic trend growth or global factors) we model both the US neutral rate and the trend growth together, capturing the covariance between the two. However, when we model both together, we get a negative coefficient for the domestic growth rate which is not straightforward to interpret (Figure 10). Part of the reason why domestic trend growth and the US neutral rates are difficult to disentangle is because of a high collinearity between the two.

Considering the combined model, which includes both trend growth and the LW US neutral rates in the neutral real rate state equation, we find the domestic neutral rate depends on the US neutral rate and a trend risk premium. The trend risk premium turn is composed by a random walk component - capturing the risk premium level - and a correction on this level that depends on domestic trend growth.

In the combined model, the coefficients for the US neutral rate are confirmed in multiple cases (Figure 10). For most of CEEMEA, trend growth results in a

Figure 10. Combined model: Trend growth and US Neutral Rate betas

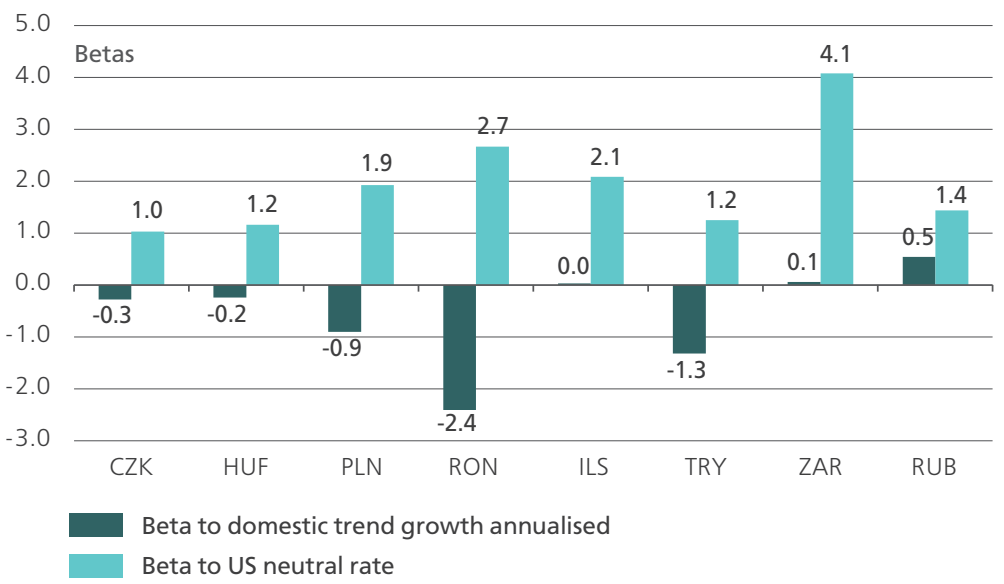

Note: Coefficients in Neutral Rate state equation, annualised for Trend Growth Source: Goldman Sachs Global Investment Research 
Figure 11. Combined model - Neutral Rates Variance Decomposition

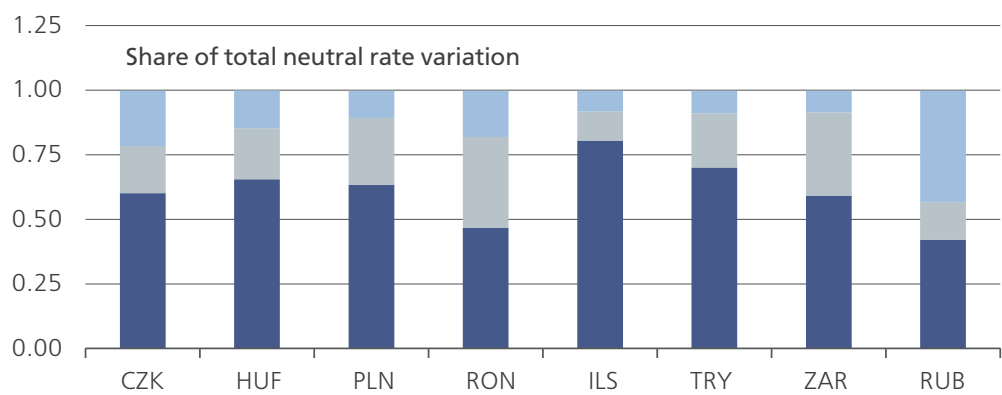

Share explained by Residual — Risk Premium adj. by growth Random Walk

Covariance

Share explained by Trend Growth and US Neutral Rates

Source: Goldman Sachs Global Investment Research

Figure 12. Russia's Neutral Rate appears to be highly correlated with the terms of trade

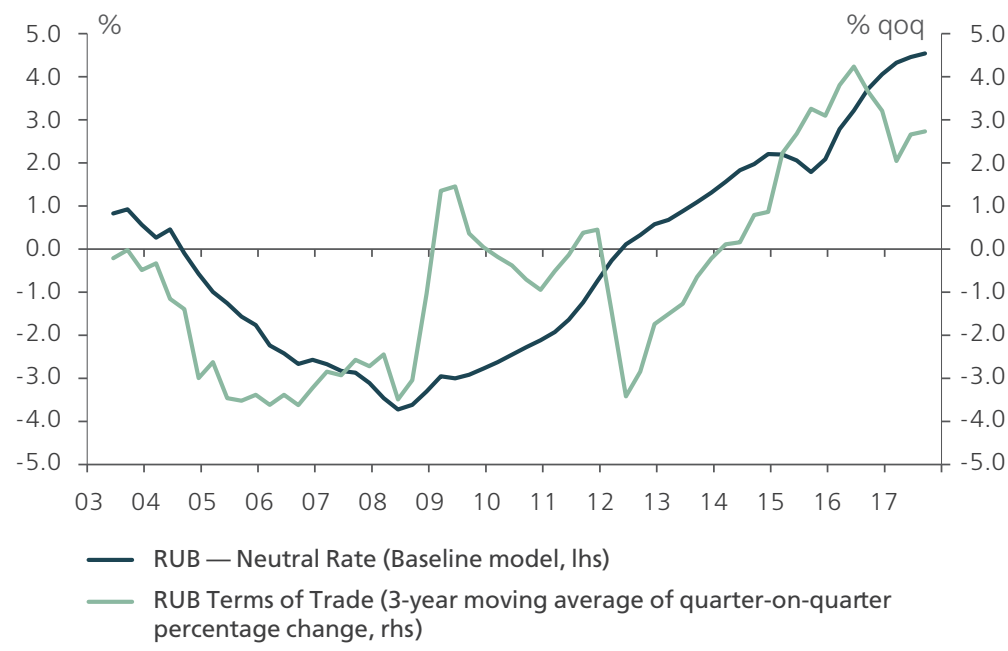

Note: Neutral rate (baseline model)

Source: Goldman Sachs Global Investment Research, Russia Statistical Office

significant correction of the risk premium (i.e., the coefficient on trend growth is negative), leaving space for a higher multiplier on US neutral rates.

The variance decomposition (Figure 11) shows that the random-walk component significantly declines in the combined model. In Russia, it is clear from the variance decomposition that only the combined model manages to effectively reduce the share of variance of the residual, and indeed the coefficient on US 
neutral rates, which was insignificant in the baseline model, becomes a sensible (and significant) 1.4 when domestic growth conditions are accounted for.

In Russia, we cannot attribute any significant part of the variation in neutral rates to either trend growth rates or US neutral rates. In fact in Russia we find a negative co-movement between neutral rates and potential growth. The most obvious source of this anomaly is Russia's more variable terms of trade. A persistent terms positive (negative) terms of trade shock will lead to upward (negative) revisions in the potential growth rate. To the extent that these persistent positive (negative) terms of trade shocks enter expectations of future terms of trade they will lead to expectations of a trend real appreciation (depreciation) and depress (increase) the estimate of neutral rates. Hence the negative correlation between trend growth and neutral rates.

Indeed, a long-run weighted average of the neutral rate and the quarter-onquarter change in the terms of trade shows a high correlation between the two, with the most recent improvement in Russia's Terms of Trade not yet being picked up by our model estimates of the neutral rate yet, which we suspect is due to the end point problem of our filter.

Figure 13. Measures of output gap is negative in Israel, Turkey and South Africa, negligible in Russia, and positive in CEE-4

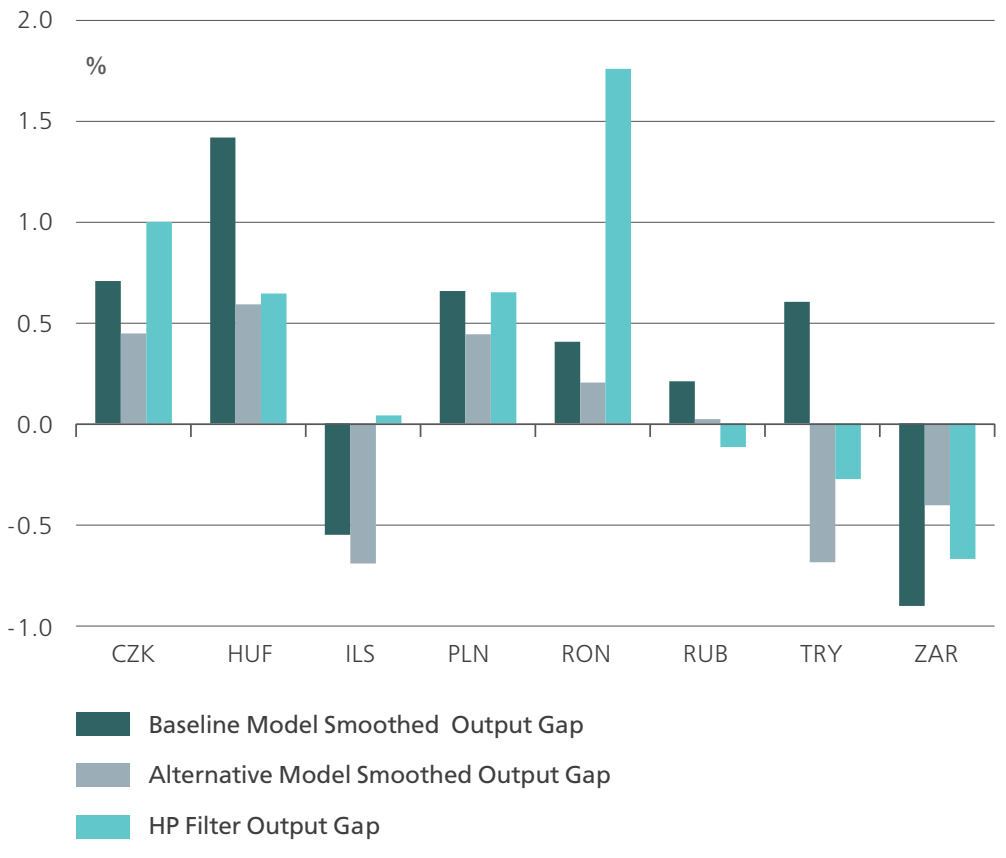

Note: Figure shows average of 2016Q4-2017Q4;

Source: Goldman Sachs Global Investment Research 
Figure 14.... while rate-gaps are negative in all of CEEMEA with the exception of Russia

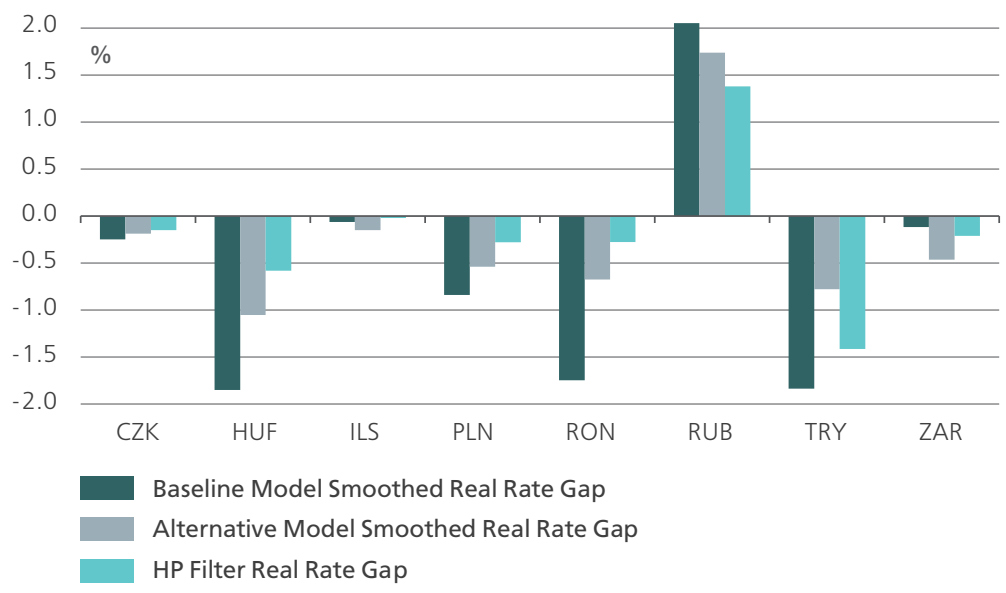

Note: Figure shows average of 2016Q4-2017Q4;

Source: Goldman Sachs Global Investment Research

\subsection{Comparison to Output Gaps}

Our estimate for neutral rates also gives an estimate for output gaps and real rate gaps across CEEMEA. These output gap measures are trend estimates (distinct from the production function-type estimates one would normally use), and allow us to gauge where policy is accommodative/ restrictive relative to the business cycle from a pure statistical framework:

- Output gaps are currently positive in the Czech Republic, Hungary and Romania, but negative real rate gaps, which suggests monetary policy here is accommodative

- Turkey, South Africa and Israel have negative output gaps and negative rate gaps

- In Russia, the current real rate is significantly above the neutral rate despite the output gap being closed, which suggests Russia is the only economy in CEEMEA with a restrictive monetary policy relative to its business cycle

\section{Robustness}

From an empirical point of view, the above results are highly sensitive to the restrictions in the parameter space, which are usually binding. In particular, one important restriction concerns the 'noise to signal' ratios, that is, the ratio of the standard deviations of the innovations of the trend component to that of the innovations of the gap component. As already argued, the objective is not so much that of correctly estimating the true parameters, but rather to find a parametrisation 
that yields trend and gap series that have dynamics close to the univariate HP filtering while interacting among them in a way that is coherently described by a theoretically grounded multivariate model.

From a theoretical standpoint, the most relevant assumption for the analysis of the natural rates dynamics is the specification of the trend real rate state equation. We have already shown results for two different options: the baseline model using domestic trend growth and the alternative model using US neutral rates as the main driver. However, it is interesting to see how the results hold up to a generalization including both factors in the state equation.

\section{Conclusion}

To conclude, using a methodology to estimate neutral interest rates close to that previously employed by the Fed's Laubach and Williams (2016), we find that neutral rates have stabilized at relatively low levels in most CEEMEA economies. Among the low yielders, neutral rates appear to be at levels close to those found in small open developed markets, like the UK or Canada. The exceptions are the Czech Republic and Israel, where neutral rates have fallen even further (and appear close to the levels in the US and Euro area). Among the high yielders, neutral rates have fallen sharply in South Africa and Turkey - with the former now lower than the latter. The main exception to this trend is Russia, where neutral rates appear to have risen. We have suggested that this peculiarity may reflect the interaction of a shift in Russian monetary policy with the dynamic of oil prices.

Our estimates for the neutral rates closely mirror the dynamics of the US neutral rate, which appears to be a better determinant of CEEMEA neutral rates than domestic trend growth (implying that global factors are more important than local factors in driving neutral real rates). The exception (again) is Russia, where terms-of-trade dynamics appear to be more important than the US neutral rate.

\section{References}

Barsky, R., Justiniano, A., and Melosi, L. (2014). The Natural Rate of Interest and Its Usefulness for Monetary Policy. American Economic Review: Papers \& Proceedings, 104(5), pp. 37-43

Bernanke, B. (2005). The Global Saving Glut and the U.S. Current Account Deficit, Board of Governors of the Federal Reserve System.

Berger, T. and Kempa, B. (2014). Time-varying equilibrium rates in small open economies: Evidence for Canada. Journal of Macroeconomics, 39, pp. 203-214.

Bouis, R., Rawdanowicz, L., Renne, J.-P., Watanabe, S., and Christensen, A. (2013). The effectiveness of monetary policy since the onset of the financial crisis, OECD.

Carrillo, J. and Poilly, C. (2014). Investigating the Zero Lower Bound on the Nominal Interest Rate Under Financial Instability, Banco de Mexico.

Grafe, C., Grut, S., and Rigon, L. (2017). CEEMEA Economics Analyst: Neutral interest rates in CEEMEA-Moving in tandem with global factors, Goldman Sachs Global Economic Research 
Giammariou, N. and Valla, N. (2003) The Natural real rate of Interest in the Euro Area, European Central Bank Working Paper Series, 233.

Hamilton, J., Harris, E., Hatzius, J., and West, K. (2015). The Equilibrium Real Funds Rate: Past, Present, and Future. In: the US Monetary Policy Forum. Available at: https://www.brookings.edu/wp-content/uploads/2016/07/WP16-Hamilton-et-alequilibrium-real-funds-rate-1.pdf

Holston, K., Laubach, T. and Williams, J. (2016) Measuring the Natural Rate of Interest: International Trends and Determinants, Finance and Economics Discussion Series 2016-073. Washington: Board of Governors of the Federal Reserve System.

Kim, C-J. and Kim, J. (2013): The 'Pile-up Problem' in Trend-Cycle Decomposition of Real GDP: Classical and Bayesian Perspectives. MPRA Paper, 51118.

Kresptsev, D., Porshakov, A., Seleznev, S. and Sinyakov, A. (2016). The Equilibrium Interest Rate: A Measurement for Russia. Economic Research Working Paper, Central Bank of Russia.

Laubach, T. (2002). Documentation of Gauss code for "Measuring the Natural Rate of Interest”. Available at: http://www.codelooker.com/dfilec/3622lwrstar/rstar_doc.pdf

Laubach, T. and Williams, J. (2003). Measuring the Natural Rate of Interest. Review of Economics and Statistics, 85(4), pp. 1063-1070.

Laubach, T. and Williams, J. (2016). Measuring the Natural Rate of Interest Redux. Business Economics, 51, pp. 257-267.

Mésonnier, J.-S. and Renne, J.-P. (2007). A Time-Varying "Natural" Rate of Interest for the Euro Area. European Economic Review, 51, pp. 1768-1784

Pedersen, J. (2015). The Danish natural real rate of interest and secular stagnation. Danmarks Nationalbank Working Papers, 94.

Perrelli, R. and Roache, S. (2014). Time-Varying Neutral Interest Rate - the Case of Brazil. IMF Working Papers 14/84.

Stock, J. and Watson, M. (1998). Median unbiased estimation of coefficient variance in a time-varying parameter model. Journal of the American Statistical Association, 93(441), pp. 349-358.

Summers, L. (2014), US Economic Prospects: Secular Stagnation, Hysteresis, and the Zero Lower Bound. Business Economics, 49(2), pp. 65-73.

Us, V. (2018). Measuring the Natural Interest Rate for the Turkish Economy. International Journal of Central Banking, 14(1), pp. 259-316.

Wicksell, K. (1936). Interest and Prices. London: Macmillan (A translation of 1898 edition by R.F. Kahn) 